\title{
Employer Engagement in Promoting the Labour-Market Participation of Jobseekers with Disabilities. An Employer Perspective
}

\author{
Rik van Berkel
}

Utrecht School of Governance, Utrecht University, Netherlands

E-mail: r.vanberke/@uu.nl

This article contributes to the literature on engaging employers in activation policies. It focuses on a specific policy aimed at promoting the labour-market participation of people with disabilities. Unlike many activation policies, this policy recognises that the engagement of employers and the human resource management practices in their organisations are crucial factors for the policy's success. The article reports on a study among employers participating in this policy. It focuses on the challenges employers experience in placing people with disabilities in their organisations, and on the public support they expect in dealing with these challenges. The article concludes that as promoting the labour-market participation of groups remote from the labour market requires social policy interventions as well as interventions in organisational human resource management, it poses challenges for policy makers, agencies providing employment services, and employers and their organisations.

Keywords: Employer engagement, disability, activation policy, HRM, employment services.

\section{Introduction}

The involvement of employers in activation policies is receiving growing scholarly attention (Ingold and Stuart, 2015; Hemphill and Kulik, 2016; Van Berkel et al., 2017; Bredgaard, 2018; Orton et al., 2018). This reflects an increasing emphasis in social policies on the involvement of employers in promoting labour-market participation. This development is denoted as a shift from a supply-side towards a demand-side orientation (Fletcher, 2004; Ingold and Stuart, 2015; Bredgaard, 2018; Frøyland et al., 2018). Whereas supply-side oriented activation policies focus at making jobseekers 'job ready' for the labour market in general, the demand-side approach addresses employers more directly. How employers are addressed varies: recent academic literature started distinguishing various forms of engaging employers (Van Berkel et al., 2017; Bredgaard, 2018; Frøyland et al., 2018). Some publications argue that these forms not only vary in terms of the policy instruments used to engage employers, but also in terms of the roles of employers in being engaged (Van der Aa and Van Berkel, 2014; Orton et al., 2018; Van Gestel et al., 2019).

In the context of activation policies, employer engagement has been defined as the active involvement of employers in addressing the societal challenge of promoting the labour market participation of vulnerable groups' (Van Berkel et al., 2017: 503). Although several studies of employer engagement make clear that the employer is indeed important 
in the engagement process (e.g. Aksnes, 2019), the concept employer engagement should not be interpreted in a narrow sense. Instead, employer engagement refers to the involvement of organisational actors in a broad sense: including, for example, top management, human resources (HR) staff, supervisors and employees (see Frøyland et al., 2018).

Employer engagement has been subject to critical reflections in the literature. Firstly, the question is raised whether employers want to be engaged in the first place. This question cannot be answered in general. A Danish study developed an employer typology based on employers' attitudes towards activation policies, and their actual participation in these policies. The study showed that among employers with a positive attitude towards activation policies only a minority actually participated ('committed employers'; Bredgaard, 2018). Another typology was developed in an Australian study that focused specifically on hiring disabled people (Hemphill and Kulik, 2016). These authors distinguished loyal hirers, light hirers, non-hirers and antagonists. They argued that employment support agencies should focus on engaging light hirers and non-hirers, thus linking types of employers to strategies for engaging employers. Secondly, there is debate about the impact of a demand-side orientation on the increasingly important activation policy goal of promoting the labour-market participation of jobseekers more remote from the labour market, such as people with disabilities (Fletcher, 2004; Gore, 2005). The issue raised by these authors is how a closer focus in activation on employers' recruitment needs can be reconciled with promoting the labour-market participation of these jobseekers.

The contribution of this article to the debate about employer engagement in activation is threefold. Firstly, the article focuses on a Dutch policy that explicitly aims to engage employers in promoting the labour-market participation of jobseekers remote from the labour market. This policy provides an opportunity to analyse how the issue of reconciling employers' recruitment needs with promoting disabled people's labour-market participation works out in practice. Secondly, the article reports on a study of employers who - in the terminology of the employer typologies developed by Bredgaard (2018) and Hemphill and Kulik (2016) - can be considered as committed and loyal employers. Their actual participation in the policy confronts them with organisational challenges in hiring and placing the policy's target group. By studying these challenges and the support employers need to deal with them, the article contributes to insights into how positive employer attitudes can be transformed into actual participation. Thirdly, we contribute to the issue of how employers can be stimulated to become engaged. We do so by focusing on what types of public support in dealing with organisational challenges they expect, and how policies and employment services stimulate or hinder engagement. Thus, we look at the 'two faces' of employer engagement (Ingold and Stuart, 2015): employers' engagement with activation policies and policy makers'/implementers' engagement with employers.

We first elaborate the various forms of employer engagement distinguished in the literature. We continue with a description of the policy that is the focus of our study. Then, we briefly present the research project itself, followed by a section discussing the main results. The final section concludes and discusses the article's contributions and limitations.

\section{Employer engagement in activation policies}

Literature discussing the rise of employer engagement in activation uses a variety of concepts: demand-oriented approach, demand-led approach, demand-side approach, matching approach, employer-oriented approach, employer orientation, combined approach 
(Fletcher, 2004; Gore, 2005; Spoonley, 2008; Sowa et al., 2015; Bredgaard, 2018; Frøyland et al., 2018; Orton et al., 2018; Castillo, 2019). To a certain extent these concepts reflect various types of employer engagement. The type that has received most attention is the demand-led approach (Fletcher, 2004; Gore, 2005; McCollum, 2012). This approach addresses employers' recruitment needs by finding suitable candidates for vacancies and training them when necessary. Several authors are critical about this approach, pointing at the reconciliation issue mentioned in the introduction. Sowa et al. concluded in a study of the German Public Employment Services (PES): ' (...) the PES risks failing to achieve the balancing act between living up to its social responsibilities and maintaining a reputation as a capable placement service provider' (Sowa et al., 2015: 508). A UK study (Fletcher, 2004) argued that as long as demand-led approaches take employers' hiring requirements as given, they are likely to reinforce rather than challenge labour-market inequalities.

Organisations' recruitment and selection practices have been identified as barriers for promoting the labour-market participation of jobseekers remote from the labour market in various studies (Devins and Hogarth, 2005; Salognon, 2007; McCollum, 2012). These studies point at processes of discrimination and stereotyping taking place in recruitment and selection, but also identify characteristics of the selection process (pre-selection based on CVs and application letters) and recruitment channels (business or employees' networks) as obstacles for jobseekers remote from the labour market. One way of addressing these obstacles is government regulation requiring recruitment and selection practices to comply with specific societal norms and values. Some authors have discussed this type of engaging employers under the heading of demand-side approaches (Bredgaard, 2018; Frøyland et al., 2018). Here, the focus is on regulating instead of facilitating recruitment and selection: through quota or anti-discrimination regulation but sometimes also through incentives such as wage subsidies and tax exemptions.

A third form of employer engagement goes beyond regulating or facilitating recruitment practices and addresses organisational human resource management (HRM) policies and practices more broadly. Here, we will use the broad definition of HRM developed by Boselie (2014: 14): 'Human resource management (HRM) involves management decisions related to policies and practices that together shape the employment relationship and are aimed at individual, organizational and societal goals'. Frøyland et al. (2018) denote this type of employer engagement as the combined approach because it focuses on both the jobseeker and the employer. This approach does not perceive HRM practices as unchangeable. Instead, support is provided to jobseekers and employers in creating a match that may involve changes at the level of the jobseeker (for example, his or her skills and qualifications) but also at the level of the organisation (for example, job design, work environment or styles of supervision). This approach is practiced in Supported Employment, Customized Employment (Griffin et al., 2008) and Supported Work programmes (cf. Perkins, 2008). However, it has not become part of mainstream activation policies. Of course - and the academic literature on vocational and occupational rehabilitation provides sufficient evidence here - this approach does not put an end to the issue of reconciling disabled people's labour-market opportunities with employers' needs. However, it deals with these tensions in a novel way, by explicitly addressing the role of HRM policies and practices in promoting or hindering inclusive labour markets.

These various types of employer engagement also involve different roles of employers (Van der Aa and Van Berkel, 2014; Ingold, 2018; Orton et al., 2018; Van Gestel et al., 2019). When the focus is on employers' recruitment needs, employers are seen as 
customers of employment support agencies. Regulation treats employers as actors striving for social legitimacy or as rational and calculating actors responding to sanctions and incentives. In the combined approach employers are addressed as partners or co-producers. These framings of employers' roles are ideal-typical. Studies have shown that not all employers want to be customers of employment support agencies, among others because they do not trust these agencies or because they have a negative or sceptical attitude towards their clients (Larsen and Vesan, 2012; Bonoli, 2014). Research also revealed that employers may find ways to skirt regulations: they have leeway in dealing with institutional pressures (Boon et al., 2009; Van Gestel and Nyberg, 2009). Finally, there is some evidence suggesting that it cannot be taken for granted that employment support agencies or employers are ready and willing to perceive their own and each other's role as that of partner (Orton et al., 2018; Van Gestel et al., 2019).

\section{Employer engagement in the Netherlands: the Job Agreement}

During the last twenty years, promoting the involvement of employers has increasingly characterised Dutch activation. This was the setting in which Dutch government and social partners reached a Social Agreement in 2013 that included what became known as the Job Agreement. The Job Agreement implied a new way of engaging employers, combining the various types of employer engagement discussed in the former section. Firstly, it involved a process of committing and responsibilising employers that was largely absent until then. Secondly, the agreement was explicitly targeted at a group of jobseekers remote from the labour market: people with physical, mental/intellectual or psychological disabilities. Thirdly, the Job Agreement made organisations' HRM policies and practices an express element of promoting the labour-market participation of this target group. For example, Ministerial information about the agreement mentioned that adjusting jobs to the capacities of the target group (job carving) and reorganising existing tasks in new functions were expected to be necessary. Thus, the Ministry conveyed a clear message that it expected employers to be willing to reconsider existing HRM practices in order to make their organisations more inclusive.

In the Job Agreement, employers agreed to create 125,000 jobs for the agreement's target group in the public and private sectors nation-wide during the period 2016-2026. The target group of the agreement is defined as persons unable to earn a minimum wage independently, due to disabilities. The public agencies responsible for activating unemployed people (the benefit agency and local welfare agencies) are responsible for deciding whether or not a jobseeker with disabilities is part of the target group. They do so through a 'wage-value assessment' procedure. The assessment compares the speed of work, quality of work and employability of target group candidates with 'average' employees not belonging to the target group. Various wage-value assessment instruments have been validated and are available to the benefit and welfare agencies. People belonging to the target group are entered into a target-group register, that currently includes about 250,000 persons. The public agencies are expected to approach employers pro-actively to stimulate them to recruit people from the target group and to facilitate them in the recruitment and placement process. Of course, employers can also take the initiative to hire people themselves. But then, they will need to verify with the public agencies whether or not a disabled person they intend to hire is part of the target group. 
Annually, specific targets are set for the number of jobs that employers need to create, amounting to 125,000 in 2026. The 'voluntary' commitment of employers to create jobs is not without obligation. When employers do not realise the annual targets, a quota regulation will become effective (regulated in the Job Agreement and Quota Act). In that case, each individual organisation employing over twenty-five employees will have to hire a specified percentage of its labour force from people belonging to the target group. Thus, in terms of regulation, the 'voluntary' approach and the quota differ considerably. For the 'voluntary' approach, all Dutch public and private employers together need to realise the annual targets. What counts is the total number of jobs that are created, not the number of organisations creating these jobs (which explains why currently no information is available on the number of organisations hiring people from the target group). When the quota regulation becomes effective (which is not the case until now), this will change. Then the focus will be on numbers of jobs created by individual employers, who will have to pay a fine individually when they do not meet the quota target.

Various policy instruments and support services have been introduced to incentivise employers. A wage-subsidy system guarantees the employees a minimum wage, while employers only pay that proportion of minimum wage that corresponds with employees' productivity, i.e. their wage value. Periodical wage value assessments take place in order to determine whether employees' productivity has increased (resulting in lower wage subsidies). The benefit and local welfare agencies can provide an external job coach, funded by the agencies, that supports employees from the target group. There is also a norisk provision that discharges employers from the obligation to pay wages during periods of sick leave of employees (in the Netherlands, employers are obliged to pay at least seventy per cent of wages during sick leave for a period of two years). During periods of sick leave, the employee is entitled to Sickness Benefit. In addition, the public agencies are expected to be able to advise employers on organisational and personnel issues they experience while implementing the Job Agreement.

Apart from these instruments and services, employers have created their own support structures. Besides some smaller regional or sectoral employer networks, a national network of employers was established called 'De Normaalste Zaak' (literally translated: 'the most normal thing') which describes itself as a network building an inclusive labour market. Currently, the network is a diverse group of about 650 organisations: including public and private organisations, large ones as well as small and medium-sized enterprises, social enterprises, etcetera. These 650 organisations represent a small proportion of Dutch organisations. And although the number of organisations actually hiring persons from the Job Agreement's target group is not known, there is no doubt that only a small proportion of them has membership of this network. However, the membership of some large organisations (such as ABN AMRO, Shell Netherlands, IBM Netherlands, ISS Facility Services, some universities) contributes to the visibility of the network, and is probably also helpful in recruiting new network members.

\section{The research project}

The research project aimed to answer two research questions. Firstly, we wanted to gain insight into the HRM challenges employers experience when creating jobs in the context of the Job Agreement. The second research question focused on the support in dealing with these HRM challenges that employers expect from public agencies. The project 
Table 1 Ten HRM challenges experienced as most pressing

\begin{tabular}{ll}
\hline \hline Cluster & Challenges \\
\hline $\begin{array}{l}\text { Challenges related to policy regulation and } \\
\text { implementation }\end{array}$ & $\begin{array}{l}\text { Diversity of regional/local regulation } \\
\text { Diversity of activation policies } \\
\text { Administration } \\
\text { Challenges related to recruitment and placement } \\
\text { Recruitment and selection } \\
\text { Challenges related to sustainable placement }\end{array}$ \\
& $\begin{array}{l}\text { Job creation } \\
\text { Personal problems of target group } \\
\text { Coaching needs } \\
\text { Career opportunities } \\
\end{array}$ \\
& Wage value assessments \\
& Sick leave \\
\hline \hline
\end{tabular}

focused on employers registered as members of the employer network 'De Normaalste Zaak' and similar networks. Obviously, these employers do not form a representative sample of all employers in the Netherlands. However, they are an interesting group for this research. Their membership of the employer networks can be interpreted as reflecting a positive attitude towards the Job Agreement. In addition, they are employing (or have recently been employing) people from the policy's target group. Therefore, they can provide insight into the challenges they experience, as well as on their needs for support.

The research project had an explorative character. It included a series of twenty-one interviews, followed by a small-scale survey. Our interviewees were persons in public and private organisations who are responsible for implementing the Job Agreement. In large organisations, these were mostly HRM staff (some large organisations have designated HRM staff for the implementation of the Job Agreement). In smaller organisations we interviewed the directors/owners. Interviews were recorded, fully transcribed and analysed using NVivo. The survey questionnaire was based on the findings of the interviews. The interviews resulted in a list of twenty-five HRM challenges, and this list formed the starting point for the survey questions. All members of the employer network De Normaalste Zaak received an invitation from the network to participate in the survey. Eventually, sixteen per cent of the network members completed the survey. In addition, some members from two smaller networks participated in the survey. In total, 113 organisations participated. Survey data were analysed using SPSS. The research project followed the ethical guidelines developed by the Netherlands Organization for Scientific Research in its Netherlands Code of Conduct for Research Integrity (NWO, 2018).

\section{Research findings}

\section{HRM challenges}

In the survey, we presented respondents with the list of twenty-five HRM challenges that resulted from the interviews. We asked them to what degree each challenge is experienced in respondents' organisations. The ten challenges experienced as most pressing are summarised in Table 1. We grouped them in three clusters that we will discuss in more detail in the following subsections. 


\section{Challenges related to policy regulation and implementation}

The first cluster concerns challenges related to Job Agreement regulation and implementation issues. One of them relates to activation policy decentralisation. Decentralisation increased room for municipal decision making concerning activation policies in general and aspects of the Job Agreement specifically. As a consequence, organisations recruiting people from the target group in different municipalities - and organisations do not necessarily have to be large to do that - are confronted with differences between these municipalities. Examples include: 1) groups within the target group of the Job Agreement that get priority $\left.{ }^{1} ; 2\right)$ the maximum duration of trial placements during which organisations and employees can find out whether there is a mutual match; 3) the wage value assessment system used; 4) the administrative work involved in receiving the wage subsidies.

I have a guy from municipality A and a young woman from municipality B. Both municipalities work in different ways; and I have two different contact persons. You need to find out how they work. (...) Municipality A is more troublesome, there I have to hand in a pay slip every month otherwise I won't get the wage subsidy. Now the guy moved from municipality A to B, so once the contract with B is settled, this problem is solved. (Hotel and catering industry, private sector, sixty employees)

This quote also points at another challenge in this cluster: the administrative burden for organisations hiring people from the target group. The third challenge in this cluster concerns the diversity of activation policies targeted at different groups. Apart from the Job Agreement, several other activation policies exist aimed at promoting the labour-market participation of specific groups of jobseekers. Employers willing to make their organisations more inclusive experience this diversity as confusing and complex, because each policy has its own instruments, incentives and target group. They strongly prefer one single policy for jobseekers remote from the labour market.

\section{Challenges related to recruitment and placement}

The second group of major challenges relates to the creation of jobs and finding candidates. As many of the jobseekers in the Job Agreement target group are low-skilled, organisations working with high-educated employees or requiring versatility and flexible employability of their personnel experience challenges to create jobs that fit with the capacities and qualifications of the target group.

What I feel and what I hear during meetings is that low-skilled people in particular have difficulties finding a job. For us it's a challenge as well to find these people a job. In production companies such as ours, where low-skilled people often end up, you need to be increasingly versatile and employable. (...) For people with work impairments, that gets difficult. (Production company, private sector, 200 employees)

In addition, several organisations point out that they have outsourced non-core activities, such as cleaning and catering. This type of activities could have provided job opportunities for the target group. 
We're a knowledge-intensive organization. (...) We outsourced cleaning, we outsourced catering, and we could have hired a lot of people [from the target group] for those tasks. Now we try to find ways so that employees can work with the catering company, the cleaning company. (...) First we need to discuss this with the management of those companies. And all these steps are necessary before you can place an employee. (Public sector organisation, 1,400 employees)

Organisations deal with challenges related to job creation and finding candidates in different ways. Some use a mainly vacancy-centred approach: organisations' recruitment is focused on finding candidates from the target group that have the skills and qualifications to fill existing vacancies.

We don't see many jobseekers remote from the labour market with an academic master's degree. When we find them, we will give them the same opportunities as everyone else here. But they are scarce. (Private services sector organisation, 140 employees)

Although this and similar organisations are willing to make minor work and workplace adjustments, existing vacancies are the starting point. In the candidate-centred approach, organisations meet candidates and then develop a job or set of tasks that fit the candidate - quite similar to the Customized Employment model. As one respondent explains:

We went to a Meet and Greet meeting organized by the benefit agency. We spoke with many candidates and received their CV. Eventually, we invited three for an interview. We asked them what they are looking for, what they like to do. What triggers you, what coaching do you need. (...) And as a result of that we found a very appropriate candidate for our customer service department, in administrative work. (General and technical support services, private sector, 10,000 employees)

The distinction between the vacancy-centred and candidate-centred approaches is more diffuse in practice than we describe it here. Nevertheless, our study revealed clear differences between organisations concerning their degree of flexibility and creativity in adjusting the design of jobs in order to make them fit the skills and capacities of candidates. 'Job carving' is one of the strategies that is used by organisations that approach the design of jobs in a more flexible way.

We use job carving: we scrape together tasks that match the target group. For us that's the main challenge. We outsourced many tasks. And skill requirements become higher and higher. (Financial services, private sector, 3,000 employees)

What these different approaches make clear is that HRM challenges are not 'objective facts', unambiguously related to disabled jobseekers' 'barriers'. The challenges that organisations experience in recruitment and job creation, we argue, are as much related to (perceived) characteristics of jobseekers' disabilities as to characteristics of organisations' HRM policies and practices. They are constructions that partly depend on the 'framing' of inclusive HRM in organisations. Some organisations frame inclusive HRM as their willingness to hire Job Agreement candidates provided that they can be matched with the ways in which jobs are designed, and meet job requirements. Whereas these 
organisations largely take existing HRM as fixed, others are more willing and able to reconsider HRM. For these organisations, inclusive HRM has a broader, more encompassing meaning that goes beyond 'fair' recruitment and hiring practices and involves the organisation of work more generally.

\section{Challenges related to sustainable placement}

A third group of challenges arises after employees are placed and sustainability of employment is at stake. Our research results show that organisations often do not know exactly what to expect from candidates in advance. They are unsure what health or other problems might arise, how the productivity and employability of employees will develop, and what coaching employees need and for how long. Organisations only discover this after working with employees for a while. It is organisations' experience that benefit and local welfare agencies often lack information about these issues as well, and are therefore insufficiently able to prepare organisations. In addition, organisations experience ethical barriers in asking candidates about these issues, even though they consider this information very important.

In selection interviews, you need to keep asking questions about disabilities. We are not used to do that. You don't ask candidates: are you ill? Are you pregnant? You're not allowed to do that. But for these candidates it is very important that you know how to support them and what they need to do a good job. So you need to know about their disability. (Public sector organisation, 380 employees)

If you don't know people well, and if external coaches or internal buddies don't know people well, you sometimes don't know what's going on. And once you find out they may be so wrapped up in misery that it takes much longer to arrange support, debt restructuring and the whole caboodle. (General and technical support services, private sector, 10,000 employees)

A final challenge concerns the wage-value assessment which, as mentioned before, is repeated periodically. According to several organisations, this assessment underestimates the importance for organisations of employees' employability in a variety of tasks. This may result in disagreements concerning employees' wage value, and eventually in terminating contracts.

A 'normal' employee can work in three, four tasks. A person with disabilities only in two. So for us, this person's employability is low. But [the benefit agency] has a different view. ( ...) I am not allowed to reason like that. (Tourism, private sector, 150 employees)

\section{Managing HRM challenges}

Although not part of the top ten of most urgent HRM challenges, respondents point at an issue that affects the management of most other challenges: the importance of involving organisational actors in the implementation process. This includes general management (especially in large organisations), supervisors and employees. HRM staff among our respondents emphasised that it is important to avoid that the Job Agreement is perceived 
as 'an HR thing'. In several organisations, HR departments hired people from the target group to set a good example and to show that HR is itself making a contribution. Some respondents mentioned the importance of general management's engagement. This helps in framing the implementation of the Job Agreement as an organisational rather than an HR priority.

For several years, it was an HR issue. Nowadays, it is an issue of general management. HR is simply one of the partners. General management made it a strategic priority of the organization. (Financial services, private sector, 3,000 employees)

For some respondents, general management engagement is part of a top-down strategy that they consider more effective than a bottom-up strategy. Others view it is part of a strategy to create organisation-wide support. These respondents do not believe that imposing the Job Agreement hierarchically will work.

I believe in inspiration. Only inspiration. Enforcement isn't going to work. (...) Give presentations, so that people can air out their barriers and prejudices regarding working with disabled people. (University, 6,700 employees)

The 'barriers and prejudices' referred to in this quote can be manifold. Several respondents mention that many people in the organisation are unfamiliar with treating people with disabilities and having them as colleagues. Mental and psychological disabilities specifically run into ignorance and sometimes even fear. There is another side to this as well: supervisors or employees that do have personal affinity with disabled people are an important asset in creating organisational support. Another issue concerns the (perceived) support needs of employees with disabilities. Supervisors and employees often consider themselves unable to provide support. They think that they do not have the skills and the time, and are afraid providing support will have a negative impact on their own performance. Hiring people with disabilities may also conflict with personnel policies more broadly. For example, organisations working with many agency workers considered it hard or impossible to support these workers - who often work for a limited number of hours or for short time periods - in working with disabled colleagues. In organisations that were cutting down on staff or had done so recently, hiring people with disabilities was considered unfair and met resistance.

But although all respondents reported difficulties in engaging organisational actors, many also mentioned examples illustrating that investing in engagement eventually pays off. As a matter of fact, creating these 'success stories' is an important part of the implementation strategy. Several organisations started with small-scale pilots - sometimes involving supervisors and employees supporting the initiative - hoping these would create success stories that could be used to expand engagement. Success stories are not only about successful placements of people with disabilities. They are also stories about how these placements create added value for supervisors and employees. For example, employees placed in the context of the Job Agreement may reduce work pressures of their colleagues by carrying out tasks that their colleagues don't get around to. But most success stories we heard referred to how working with disabled people results in workplace enrichment. 
Initially, some colleagues find it difficult to work with persons with disabilities. But gradually, they [the colleagues] develop, so it cuts both ways. That is great. (Media company, private sector, thirty employees)

For many of our on-call employees their job here is their first work experience. It is funny to see that at the end of the season, they developed a broader view of man. (Tourism, private sector, 150 employees)

I went to that department [to provide information about the Job Agreement], and I met these highly educated people. They all dug their heels in. 'Impossible, to place someone like that here', was their reply. Then we started job carving, and eventually that was the first department where we placed someone. And now they love it. (Public sector, 380 employees)

\section{Public support}

The organisations expect support in dealing with the challenges from the benefit agency and local welfare agencies. The proportion of organisations expecting support in dealing with HRM challenges is different for each of the challenges. Not surprisingly, some of the most pressing HRM challenges that organisations experience (see Table 1) are also mentioned frequently as issues where they expect public support. Ninety per cent or more of the organisations expect public support concerning the issues of local/regional and activation policy diversity, and in recruitment and selection. These are issues where the public agencies can make a difference. They are potentially able to harmonise regional and local regulations and they also know what persons are registered as belonging to the target group.

Nevertheless, HRM challenges experienced as pressing do not always result in high public support expectations. For example, creating jobs for candidates is considered a pressing challenge, but only forty per cent of organisations expects public support. Maybe organisations consider this an internal issue and do not want external scrutiny; maybe they do not think - or do not know - that public agencies are able to support them. The reverse takes place as well. There are some challenges that employers do not consider particularly pressing but where many of them do expect public support. For example, eighty-six per cent of employers in our survey expect public agencies to provide insight into the capacities and limitations of employees from the target group; this issue is not part of the top ten of most pressing HRM challenges. Several respondents seemed quite surprised to discover that public agencies do not know their clients very well.

[about the benefit agency:] They don't invest in trying to know their clients. 'You have a disability, what's wrong with you? Oh, autism. And what would you like to do? Oh, you like to work in the hotel and catering industry'. And then they call me, they don't ask candidates additional questions. (Hotel and catering industry, private sector, sixty employees)

The limited knowledge that public agencies have of their clients makes the trial placement an important opportunity for employers. A large majority of organisations expects public support in using this opportunity, although making use of a trial period is not experienced as a major HRM challenge. In this case this might simply mean that public support is experienced as adequate. 
In some cases, dissatisfaction with public support stimulates employers to find private solutions. For example, some organisations prefer internal over external job coaches. Others decided to involve private recruitment agencies in finding employees with disabilities.

At some point we had eight different external job coaches for eight employees. And when they visit me, they all want to talk about soccer. (...) Then I thought, this is not about coaching girls and boys. And then we started a pilot to work with internal job coaches. And that was great. (Tourism, private sector, 150 employees)

\section{Conclusion and discussion}

This article looked at the engagement of employers in a specific activation policy aimed at jobseekers remote from the labour market: the Dutch Job Agreement. This policy combines elements of various types of employer engagement. It regulates organisations' recruitment decisions through annual job creation targets and, when targets are not realised, a quota. The Job Agreement also includes elements of facilitating employers: meeting organisations' recruitment needs is considered an important motivator for employers to become engaged. At the same time, the policy goes beyond facilitating organisations by trying to intervene in their HRM policies and practices. It considers these policies and practices part of the problem and part of the solution in promoting the labourmarket participation of groups remote from the labour market. In this respect, the policy can be considered innovative: never before - at least in the Dutch context - have policy makers, policy implementing agencies and employers acknowledged so explicitly that promoting the labour-market participation of these groups of jobseekers requires joint social policy and HRM policy efforts.

This does not mean that creaming processes do no longer take place, and that reconciling public policy objectives and organisational goals is completely successful. For example, one of the first Job Agreement evaluation studies showed that employers are more willing to hire people with physical disabilities than other types of disabilities (Adelmeijer et al., 2015). A recent evaluation (Fris et al., 2019) showed that for people with severe intellectual disabilities, who used to find work in sheltered employment but are now expected to work in the 'regular' labour market under the Job Agreement, job opportunities have decreased. This has already raised a debate that the Job Agreement may be successful for some groups, but that for others sheltered employment should remain available.

Employers' willingness to become engaged in activation policies is a major concern for policy makers. In this article, we pointed at empirical studies that developed typologies of employers. Our own study provided additional insights into the issue of employer diversity by pointing at the various ways organisations frame inclusive HRM. Using the vacancy-centred and candidate-centred approaches as extremes we concluded that the ways in which organisations frame inclusiveness, and perceive the HRM efforts it requires, differ. For policy makers and public support agencies, these insights into employer diversity are highly relevant. They imply that a range of policy instruments and employer services is needed to be responsive to what might trigger organisations to become engaged. Public agencies also require sensitivity in estimating organisations' readiness to reconsider their framing of inclusive HRM, as these frames are not necessarily set in stone. 
Our study shows that employers need more than motivation to actually participate in policies such as the Job Agreement. Hiring and placing employees with disabilities raises HRM challenges including, as we saw, promoting the engagement of organisational actors in dealing with these challenges. Some employers will not be restrained by these challenges, but for others they may be reasons to discontinue or refrain from participation. Support systems that help organisations bridge the gap between motivation and participation are therefore important. For public agencies, being responsive to employers' support needs and expectations is not going to be easy. It requires expertise in areas that are not readily available, as the agencies have no tradition in delivering this type of employer-oriented support. At the same time, the development of responsive and tailormade employer-oriented support is vital. Dissatisfaction with public support may encourage employers to opt-out of the Job Agreement, which might jeopardise the successfulness of the policy. Thus, the nature of, and experiences with, collaboration between public agencies and employers will be an interesting issue for future research.

Our study exclusively focused on the employer (or HR staff) perspective. This implies that our study has some limitations that could be addressed in future research. The first limitation concerns the absence of the experiences of people with disabilities themselves. Do they experience the way organisations perceive and address HRM challenges as supportive in promoting their labour-market participation in general, and their inclusion in the organisation specifically? The second limitation concerns the role of other organisational actors, especially supervisors and colleagues of employees with disabilities. Are their support needs in supporting and collaborating with employees with disabilities sufficiently addressed by policies, public services and organisational HRM policies and practices?

Finally, we argue that studying 'motivated' and 'participating' - in short, engaged employers is valuable. Their experiences with engagement and collaborating with public agencies provide crucial lessons. When these vanguard employers get de-motivated because of the HRM challenges they experience, the complexity of policies, or the quality of support they receive, it will be far more difficult to engage less motivated employers. Framed positively, enthusiastic employers that share successful experiences with colleague employers are likely to be a crucial factor in increasing the number of motivated and participating organisations (cf. Hemphill and Kulik, 2016).

\section{Acknowledgements}

For this study, we received a grant from the Dutch Research Council (NWO), file number 400.17.603. The project was carried out in collaboration with Dr Charissa Freese and Dr Irmgard Borghouts from Tilburg University, the Netherlands. I would like to thank three anonymous reviewers for their constructive comments and suggestions.

\section{Note}

1 For example, although part of the Job Agreement's target group is not entitled to benefits, municipalities are inclined to prioritise benefit recipients because this helps municipalities to reduce local benefit expenses. 


\section{References}

Adelmeijer, M., Schenderling, P., Heekelaar, M., Oostveen, A. and Beerepoot, R. (2015) Onderzoek Participatiewet Bij Werkgevers, The Hague: Berenschot.

Aksnes, S. (2019) 'Engaging employers in vocational rehabilitation: understanding the new significance of knowledge brokers', Journal of Vocational Rehabilitation, 50, 1, 73-84.

Bonoli, G. (2014) 'Employers' attitudes towards long-term unemployed people and the role of activation in Switzerland', International Journal of Social Welfare, 23, 4, 421-30.

Boon, C., Paauwe, J., Boselie, P. and Den Hartog, D. (2009) 'Institutional pressures and HRM: developing institutional fit', Personnel Review, 38, 5, 492-508.

Boselie, P. (2014) Strategic Human Resource Management. A Balanced Approach, London: McGraw Hill.

Bredgaard, T. (2018) 'Employers and active labour market policies: typologies and evidence', Social Policy and Society, 17, 3, 365-77.

Castillo, D. (2019) 'Employer-oriented labour market policies in Sweden: creating jobs and the division of labour in the public sector', International Social Security Review, 72, 2, 75-95.

Devins, D. and Hogarth, T. (2005) 'Employing the unemployed: some case study evidence on the role and practice of employers', Urban Studies, 42, 2, 245-56.

Fletcher, D. R. (2004) 'Demand-led programmes: challenging labour-market inequalities or reinforcing them?', Environment and Planning C: Government and Policy, 22, 1, 115-28.

Fris, P., Witkamp, A. and Walz, G. (2019) Meer kansen voor mensen met een arbeidsbeperking? Evaluatie Wet banenafspraak en quotum arbeidsbeperkten, Zoetermeer: Panteia.

Frøyland, K., Andreassen, T. and Innvær, S. (2018) 'Contrasting supply-side, demand-side and combined approaches to labour market integration', Journal of Social Policy, 48, 2, 311-28.

Gore, T. (2005) 'Extending employability or solving employers' recruitment problems? Demand-led approaches as an instrument of labour market policy', Urban Studies, 42, 2, 341-53.

Griffin, C., Hammis, D., Geary, T. and Sullivan, M. (2008) 'Customized employment: where we are; where we're headed', Journal of Vocational Rehabilitation, 28, 3, 135-39.

Hemphill, E. and Kulik, C. (2016) 'Which employers offer hope for mainstream job opportunities for disabled people?', Social Policy and Society, 15, 4, 537-54.

Ingold, J. (2018) 'Employer engagement in active labour market programmes: the role of boundary spanners', Public Administration, 96, 4, 707-20.

Ingold, J. and Stuart, M. (2015) 'The demand-side of active labour market policies: a regional study of employer engagement in the Work Programme', Journal of Social Policy, 44, 3, 443-62.

Larsen, C. and Vesan, P. (2012) 'Why public employment services always fail. Double-sided asymmetric information and the placement of low-skill workers in six European countries', Public Administration, 90, 2, 466-79.

McCollum, D. (2012) 'The sustainable employment policy agenda: what role for employers?', Local Economy, 27, 5/6, 529-40.

NWO (2018) Netherlands Code of Conduct for Research Integrity, The Hague: NWO, https://www.nwo.nl/ en/policies/scientific+integrity+policy/netherlands+code+of+conduct+for+research+integrity [accessed 16.12.2019].

Orton, M., Green, A., Atfield, G. and Barnes, S. (2018) 'Employer participation in active labour market policy: from reactive gatekeepers to proactive strategic partners', Journal of Social Policy, 48, 3, 511-28.

Perkins, D. (2008) 'Improving employment participation for welfare recipients facing personal barriers', Social Policy and Society, 7, 1, 13-26.

Salognon, M. (2007) 'Reorienting companies' hiring behaviour: an innovative 'back-to-work' method in France', Work, Employment and Society, 21, 4, 713-30.

Sowa, F., Reims, N. and Theuer, S. (2015) 'Employer orientation in the German public employment service', Critical Social Policy, 35, 4, 492-511.

Spoonley, P. (2008) 'Utilising a demand-led approach in a local labour market', Local Economy: The Journal of the Local Economy Policy Unit, 23, 1, 19-30. 
Van Berkel, R., Ingold, J., McGurk, P., Boselie, P. and Bredgaard, T. (2017) 'Editorial introduction: an introduction to employer engagement in the field of HRM. Blending social policy and HRM research in promoting vulnerable groups' labour market participation', Human Resource Management Journal, $27,4,503-13$

Van der Aa, P. and Van Berkel, R. (2014) 'Innovating job activation by involving employers', International Social Security Review, 67, 2, 11-28.

Van Gestel, N. and Nyberg, D. (2009) 'Translating national policy changes into local HRM', Personnel Review, 38, 5, 544-59.

Van Gestel, N., Oomens, S. and Buwalda, E. (2019) 'From quasi-markets to public-private networks: employers' engagement in public employment services', Social Policy and Administration, 53, 3, 434-48. 